\title{
INNOVATION IN RECRUITMENT AND TALENT ACQUISITION: A STUDY ON TECHNOLOGIES AND STRATEGIES ADOPTED FOR TALENT MANAGEMENT IN IT SECTOR
}

\author{
Sajin Jose \\ Gandhi Institute of Technology and Management, \\ GITAM University, Visakhapatnam, Andhra Pradesh, India \\ Dr. P. Asha \\ Asst. Professor, Gandhi Institute of Technology and Management, \\ GITAM University, Visakhapatnam, Andhra Pradesh, India
}

\begin{abstract}
Talent acquisition and recruitment are the undergoing processes that also essential for the organization, but it also created challenges for the company to leverage the social network, aggressively market their employment brand and recruit employee every day. In order to ensure itself successfully, it is essential for the company to constantly attract the new talent and recruit the Talent that is already in the plan. In respect to this, the traditional staffing team replaced by the strategic talent acquisition function by making focus on building on employment brand, Sourcing people in a new place with the help of social media tool, creating an opportunity for the internal candidates and leveraging the use network of referral by making relationship within the company. The study mainly focuses on the innovation in recruitment in talent acquisition by making a study on Technologies and strategies which are adopted by the talent management in the IT sector. Apart from this, the study also provides a complete background of the study by discussing the different and new methods for the recruitment process that highly focused on the uses of Technologies and other strategies adopted to acquire the Talent in the IT sector. Apart from this, the study also presents literature review which focuses on various articles, books, and journals which mainly examine a talent acquisition in a global knowledge economy and also describe the innovative tool for recruitment in the IT sector. The study also describes the Talent acquisition strategies which was adopted in the IT sector and also developing the conceptual framework effectively. In addition to this, the study also describes the finding and discussion section which includes the summarised literature, signifying the major concept that understandable in the study and at last the conclusion also described in this section.
\end{abstract}

Key words: Recruitment, Talent Management, Information Technology. 
Cite this Article: Sajin Jose and P.Asha, Innovation in Recruitment and Talent Acquisition: A Study on Technologies and Strategies Adopted for Talent Management in IT Sector. International Journal of Marketing and Human Resource Management, 10(2), 2019, pp. 1-8. http://iaeme.com/Home/issue/IJMHRM?Volume=10\&Issue $=2$

\section{INTRODUCTION}

Innovation is essential in every business because it encouraged the organization by identifying the impact on the business as per the process leading to ensure the higher productivity in an effective way. In order to make focus on the keyword "innovation", it can be related to the development of unique and adoption of new technologies and implementation of Technologies by adopting creative work process. It also includes engagement of employees and the creation of new business design models so that the firms will get a better output in an effective way. In the present time, innovation is related with the human resource strategies that mainly manage the talent in the workforce which is in the form of identifying the strength of the organization and behaviour of the employees and make effective coordination between the organization and employees (Kamran, Dawood \& Hilal, 2015). In order to make a focus on recruitment, it can be said that it is a process that highly attracts applicants who want the job. In order to adopt the different methods for recruitment process by the HR manager in IT sector, it can be said there are various method suggest inclusive job advert programmatic, advertising, video interviewing, benefit from gig economy, engaging with passive candidates, employee refers, texting, social media, virtual reality using data employee review side, aging workforce management and mobile recruitment are the major Strategies and methods that are adopted by the HR manager to recruit new talent in the workplace (Hughes \& Rog, 2008).

In today's competitive world, it is essential for every business to ensure high skilled labor and workforce so that they will be able to achieve the desired target by increasing their profitability level in a great scale (Breaugh, 2016). In respect to this, it is essential for HR professionals to adapt those technologies and strategies that highly used to acquire the Talent, especially in the IT sector. In respect to this, talent acquisition is known as long-term strategic efforts by identifying the qualified people by making the effective relationship and also provides convenience by convincing them to bring their unique skill to the company. There are various IT sectors and IT developing companies highly focus on the collecting and using data to make talent decision under which the recruiter make a data-driven decision by the use of a process which great understanding of how and why someone will be a good fit in a workplace. In respect to this, there are various modern recruiting tools such as long-term Matrix, live performance retention and over of fit has been used by the HR manager.

In addition to this, the company also focus on working with another department to integrate Talent Acquisition. There are various companies in which the marketing manager help to employee the brand and attract the continent by using various recruiting materials which are in the form of video that highlight the culture of the company and also using automation, Artificial Intelligence and machine learning which are the best technological tools which is known as a modern recruiting methods and adopted by the recruiters and HR leader to stay connected with the top talent. Under the artificial intelligence tool, it is easy for the manager to predict the human behavior and it also helpful for the candidates to determine the actual and current performance of the company because under this, the company highly focused on updating the social profile so that they will be able to attract the candidates in an effective way (Kaplan, Khan \& Roberts, 2012). In addition to this, automation is also known as a powerful technique or tool which highly used for screening the resumes, acknowledging and rejecting applicants, scheduling the interviews and checking the references effectively. As a result, it can be said that by the use of Artificial Intelligence and automation tool, there are $15 \%$ of the HR leader working in IT sector highly effect with the workforce plan (Bitte, 2017). 
Thus, it can be said that innovation plays a vital role in recruiting and acquiring the Talent official in the IT sector. In today's world, there are various technologies and strategies adopted by the IT sector in order to manage talent. The human resource plays an important role in handling the performance of an organization by ensuring its effectiveness and talent has grown to become Chief differentiation for the management of performance in leveraging the competitive advantage (Huselid, 1993). The study is vertically focused on how innovation in their technologies are used as a method of recruiting the correct talent and for managing the talent in the IT sector. The motivation behind the conducting this research is the scarcity of literature pertaining to innovation in recruitment and talent acquisition in IT industry which is the prominent contributed to the economy of the nation (Bhatnagar, 2007).

\subsection{Aims and Objectives}

Every research study has a primary aim based on which the study is developed. The primary aim of the research study is to study the role of innovation in the domain of recruitment and talent acquisition in the IT (Information Technology) industry

Based on the research study, some secondary objectives will also be considered in the same context in order to acquire greater insight and profound knowledge on the topic of research and develop the study further. Therefore, the present study will address the following tentative objectives:

- To evaluate the use of the latest technologies by the HR department in IT companies for recruiting

- To assess the HR strategies deployed by the IT companies for talent management

- To estimate the effectiveness of innovation, technologies and HR strategies in recruiting suitable talent for the IT companies

\section{LITERATURE REVIEW}

\subsection{Talent Acquisition in the Global Knowledge Economy}

According to Boxall \& Purcell (2004); English \& Baker (2006) talent acquisition is important to process which highly adopted by the organization which totally depends on the success and failure of the firm. Talent acquisition also is known as the most important human resource activities, job and people must be matched correctly to ensure what employee satisfaction and organizational effectiveness. Due to the emergence of the knowledge economy, it is confirmed by the world that the dramatic changes have been found in the working pattern over 15 to 20 years. As a result, people and organization are not separated with each other and people are known as the center of knowledge management. In order to achieve the competitive advantage in a knowledge economy, it is essential for the organization to ensure the skills and knowledge of the employees by managing the knowledge of people but it is also essential for the company to manage the proprietary Technology system and its people.

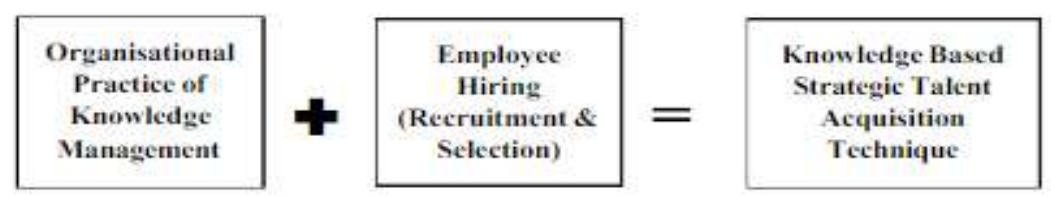

Figure 1. The equation of knowledge based talent acquisition technique generation

According to Haas (2008), the main purpose of knowledge management is to leverage and reuse the organizational intellectual capital in order to maximize the effect. In respect to this, organizational talent acquisition is helpful to get the right number of people at the right skill set 
at the right time in the right place to do the job. In respect to this, the organization can do this by making effective alignment between the knowledge management Strategies and recruitment of employees and their selection process.

As per Hubbard (2007), talent management is traditionally matched with the people skill to the specific requirement. In today's world, the organization is facing the increasing demand for the knowledge and competence of people so that it is essential for the organization to match the wider context of the working within the organization. The term "person job fit" is transformed into the "person organizations fit" because the high-performance organization highly related to the value on their recruitment and selection process and attach low critically in a developing a strategy knowledge-based talent acquisition process. In respect to this, there various strategies for acquiring the knowledge for acquiring the Talent based on the knowledge management has been used by the organization which are in the form of developing people in which the business highly related to the organization vision by actively support and providing facility to the Employees and developing Strategies for identifying recruiting and having the best talent and generalized them (Jones, 2006).

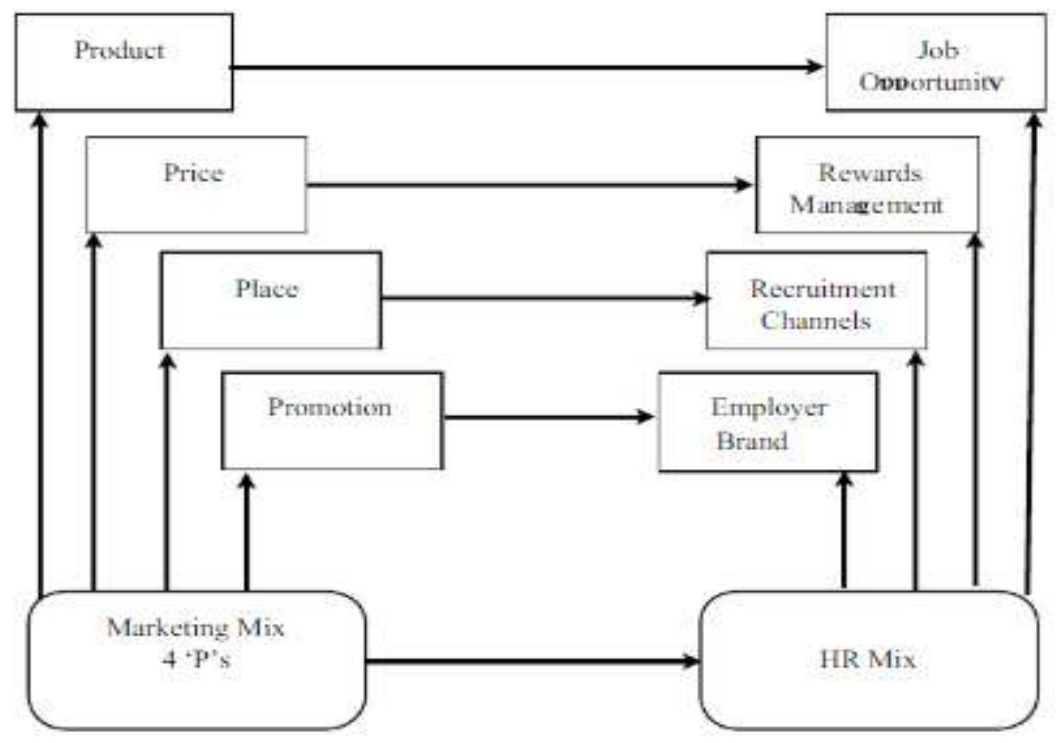

Figure 2. HR matrix

As per N. S. Rajan (2007) also examined the 4P's which will include the product, price, place, and position as a part of HR metrics in order to acquire good talent in an effective way. Moore (2006), said that significant relationship between the knowledge-based talent acquisition and competitive advantage which are based on Knowledge product and resource that Health Organisation to achieve a competitive advantage by focusing other. In addition to this, resourcebased management also increases the organization to focus on the knowledge and its acquisition creation within the firm. For example, the various IT companies like Microsoft, Wipro, Infosys make fewer assets other than knowledge of their employees and contributed by adopting continuous success in the large organization such as 3 and HP and GlaxoSmithKline. Thus, it can be said that knowledge management based talent acquisition process is a part of achieving a competitive advantage by improving the performance and growth of the organization. It also expands its span by observing the emergence and growth of the knowledge economy in society and knowledge management in the organization (Stone, 2002).

\subsection{Innovative Tools for Recruitment in the IT Sector}


According to Khaki, Erfanian Khanzadeh and Babaki Rad (2017), in the field of recruitment and talent acquisition, it is essential for the organization to hire that person who is fit for a particular job. In respect to this, there are various Strategies and technique has been used by the organization in order to ensure a good workforce that makes a direct impact on the scale of the organization. The IT companies highly focused on providing and developing a better connection within the market and leading to a bigger opportunity. In order to make focus on the new and emerging Strategies for recruiting by the use of Technologies and innovative tools such as recruitment software applicant tracking system, social networking sites, video interview and use of artificial intelligence plays an important role.

In order to make focus on big data analysis, it is known as a new recruiter superpower by which the recruiter and manager or talent professional deriving the new recruitment trends that highly make great impact on the company's hire new talent by the using of data for talent acquisition in increase the volume of data and it also provides the IT sectors with inside that helps to recruit manager. As a result, the hiring managers and recruiter highly used big data analysis as a strategic decision, for example, there are various companies like JetBlue, Wipro, Infosys highly adopted leveraging data to help the right candidate and manage and higher the top talent effectively.

As per Nilam Oswal, (2018), artificial intelligence is also becoming one of the most important innovative tools that highly effects and makes a strong foothold in recruiting. As per the survey conducted by human resource in the year of 2017, it was found that about $15 \%$ of the HR leader in over 40 countries believe the automation and Artificial Intelligence and highly impact the workplace AI-based technology include the chatbot, CV screening with the help of AI. The process for searching the candidate as per the matching criteria it also reduces and the workload especially the repetitive task in the IT sector and improve the general customer experience by saving the time resources effectively with the help of AI tools. The social media recruitment is another the form of recruiting process by the help of innovative tools which are used in the form of various social networking sites like Facebook Twitter LinkedIn. As a result, it was found that $94 \%$ of the Talent acquisition manager highly preferred networking on social media to look out the best talent in an effective way. Apart from this, recruiting software and applicant tracking system also help to increase the efficiency of the process. As a result, it was found that $70 \%$ of the IT companies are using application tracking system beneficial for the CV screening. This software helps to acquire the Talent by analyzing the document of employees required in making Association between the recruitment history and activity and also ensure compliance under the different State Law and government talent recruitment.

Video interview is another part of the recruitment process by the help of derivative tool and technique of teleconferencing technology that increase the telecommuting and it was found that approximately $60 \%$ of the IT organization and turning to video interview for the recruitment exercises because under this process there is no need of any kind of resumes and screening candidates because it can be done in a face to face interview. As a result, the various teleconferencing software such a zoom, vantage, interview4 are available that help the manager to hire and recruit the right person in the right place in the IT sector.

\subsection{Talent Acquisition Strategies in the IT Sector}

According to Syed Mansoor Pasha \& Prof. Badiuddin Ahmed (2017), in order to make focus on talent management strategies adopted by the IT sector, it mainly concerned about the alignment between employer and Strategies and retaining them so that the organization will be able to achieve the competitive advantage in the market. The talent management process mainly includes the workforce planning, to make a workforce plan by providing plans, compensation budget and having a target for the total year duration. It also includes the recruiting which is 
the integrative process of recruitment and assessment by everything. Onboarding is another process of talent acquisition under which organization train and develop the employees by providing productive and integrative Strategies and training so that the company more quickly ensure the productivity level with the help of employees in a long time basis. Apart from this, the performance management also helps to frame the places, plants by establishing its own process to measure and manage the employees. The training and performance support another part and process of talent acquisition. IT sector adopt the latest technology also provide instruction to the Employees who understand the functionaries and the different level. In addition to this, the succession planning also moves the personal into the new position by adopting some changes in the organizational system. It enables the manager and individual to identify the right of the candidate in any position. At last, the compensation and benefit also play an important role that motivates the employees and acquired Talent by critical skill gap analysis that overlooks the various Industries organization and identifies the skill gap effectively.

\subsection{Hypothesis}

$\mathbf{H}_{\mathbf{0}}$ : The role of innovation is noteworthy in the domain of recruitment and talent acquisition in the IT industry.

$\mathbf{H}_{1}$ : The utilization of latest technologies by the HR departments in the IT companies for recruiting creates a remarkable impact.

$\mathbf{H}_{2}$ : HR strategies are significant for talent management as deployed by the IT companies.

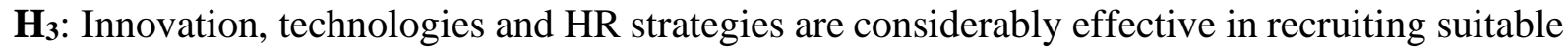
talent for the IT companies.

\subsection{Conceptual Framework}

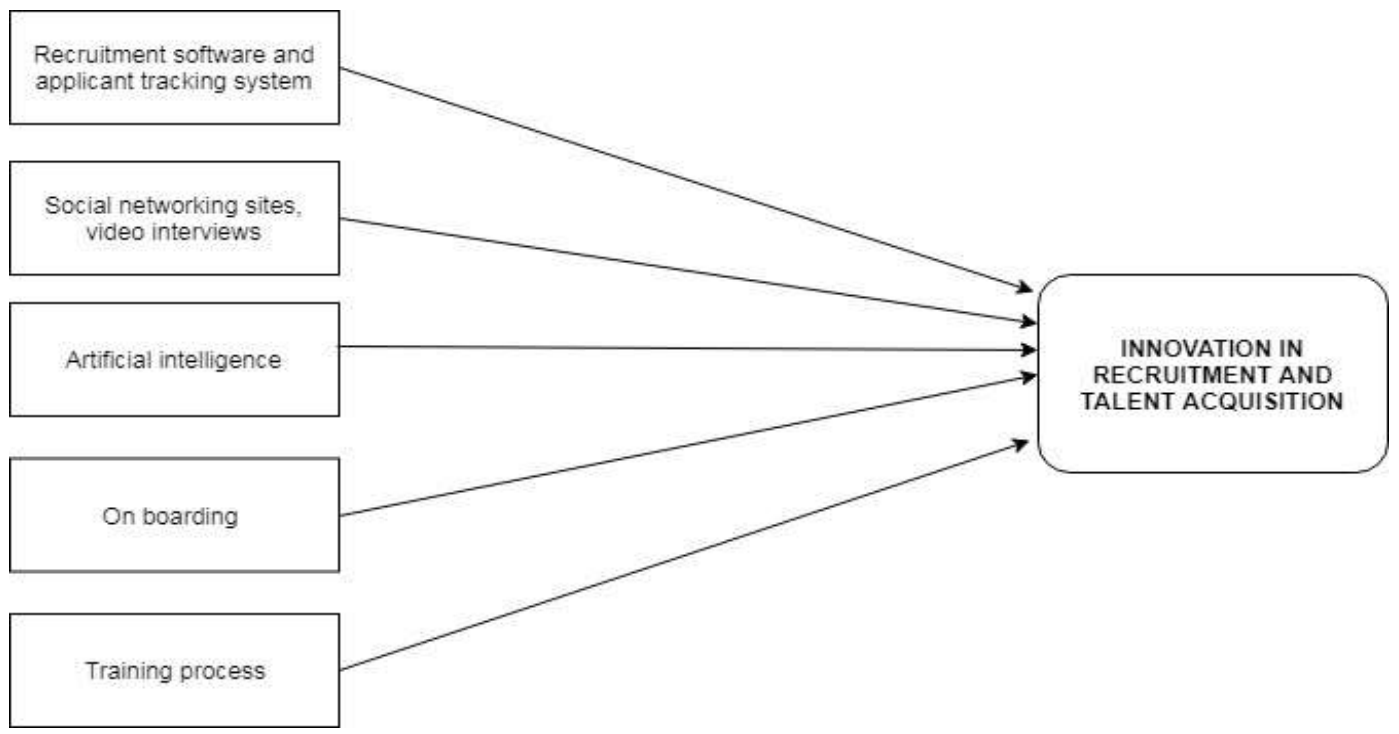

Figure 3. Conceptual framework

\section{FINDINGS AND DISCUSSION}

As per the detailed information collected and reviewed by the help of literature review and various articles and facts, it can be said that the main motive of the study is to make focus on the innovation in recruitment in talent acquisition by special focus on IT sectors. The innovation plays an important role in acquiring the talent and adopts the various Technologies and Strategies such as big data analysis, artificial intelligence, chatbot, social media, video 
interview, teleconferencing that highly affect growth and development of the organization by acquiring the skilled workforce in the workplace. In the present study, it provides complete information about the knowledge management with respect to the Talent acquisition and also provides the important role of human resource for enhancement of the performance and Organisation as well as effectiveness. Apart from this, the study also indicates some challenges because of the continuous development in the field of science and technology, the competition has been increased in the contemporary world of business. As a result, it is essential for special IT sector to meet the external requirement as well as maintaining the workforce in an effective way by attending the objective and becoming is globally successful.

\section{CONCLUSION}

As per the above-detailed report, it can be said that the main motive of the study is to analyze the role of innovation in recruiting and talent acquisition. The study also focuses on the various Technologies and strategies adopted for talent management in the IT sector. Apart from this, the study also examined the use of the latest technology by the HR department in IT Company for recruiting the right person in the right place. Moreover, the study also accesses HR strategies is deployed by IT companies for talent management and also activate the effectiveness of innovation Technologies and HR strategies in recruiting suitable talent for the IT companies effectively.

\section{REFERENCES}

[1] Bhatnagar, J. Talent management strategy of employee engagement of Indian ITES employees: key to retention. Employee Relations, 29(6), 2007, pp. 640-63. Retrieved from: https://www.researchgate.net/publication/235264272_Talent_Management_Strategy_of_E mployee_Engagement_in_Indian_ITES_Employees_Key_to_Retention

[2] Boxall, P. HR strategy and competitive advantage in the service sector. Human Resource Management Journal, 13(3), 2003, pp. 5-20. Retrieved from: https://pdfs.semanticscholar.org/be8f/1753985241c813e4c9931a5b6bcd046f44b3.pdf

[3] Breaugh, J. Talent acquisition: A guide to understanding and managing the recruitment process. Society of Human Resource Management, 2016. Retrieved from: https://www.shrm.org/hr-today/trends-and-forecasting/special-reports-and-expertviews/documents/talent-acquisition-recruitment.pdf.

[4] Hughes, J., and Rog, E. Talent management: A strategy for improving employee recruitment, retention and engagement within hospitality organizations. International Journal of Contemporary Hospitality Management, 20(7), 2008, pp. 743-757. Retrieved from: https://www.emeraldinsight.com/doi/abs/10.1108/09596110810899086

[5] English, M. J., and Baker Jr, W. H. (2006). Rapid knowledge transfer: The key to success. Quality Progress, 39(2), 2006, p. 41. Retrieved from: http://asq.org/qic/displayitem/index.html?item $=20414$

[6] Haas, M. Know Better. HR Monthly, (2), 2008, pp. 40-43.

[7] Hubbard, G. Wheel of fortune. HR Monthly, (7), 2007, pp. 30-32. Retrieved from: https://www.academia.edu/4901106/Emergence_of_the_Knowledge_Economy_and_Kno wledge_Management_and_their_Importance_in_the_Talent_Acquisition_Front

[8] Huselid, M.A. Estimates of the impact of human resource management practices on turnover and productivity, paper presented at the Annual Meeting of Academy of Management, Atlanta, GA, 1993. Retrieved from: http://www.markhuselid.com/pdfs/articles/1995_AMJ_HPWS_Paper.pdf

[9] Jones, R. People don't leave bad organisations, they leave bad managers. Integrated System Models, 2006. Retrieved from: 
https://www.academia.edu/4901057/Importance_of_Knowledge_Management_and_Kno wledge_Economy_in_Talent_Acquisition

[10] Kamran, A., Dawood, J., and Hilal, S. B. Analysis of the recruitment and selection process. In Proceedings of the Ninth International Conference on Management Science and Engineering Management (pp. 1357-1375). Berlin, Heidelberg: Springer, 2015. Retrieved from: https://www.academia.edu/25379966/Analysis_of_the_Recruitment_and_Selection_Proce ss

[11] Kaplan, J., Khan, N., and Roberts, R. Winning the battle for technology talent. McKinsey and Company, 2012. Retrieved from: https://www.mckinsey.com/businessfunctions/digital-mckinsey/our-insights/winning-the-battle-for-technology-talent

[12] Khaki, I., Khanzadeh, H. E., and Rad, A. B. Talent management and innovative behavior based on the mediating role of organizational learning. International Letters of Social and Humanistic Sciences, 79, 2017. Retrieved from: https://www.scipress.com/ILSHS.79.16

[13] Moore, M. Thinking for a Living: How to get better performance and results from knowledge workers. Human Resource Planning, 29(1), 2006, pp. 52-53. Retrieved from:

https://www.academia.edu/4901106/Emergence_of_the_Knowledge_Economy_and_Kno wledge_Management_and_their_Importance_in_the_Talent_Acquisition_Front

[14] Oswal, N. The latest recruitment technology trends and how to really use them. PC World, 2018. Retrieved from: https://www.pcworld.idg.com.au/article/633219/latest-recruitmenttechnology-trends-how-really-use-them/

[15] Bitte, R. Top three talent acquisition strategies of 2017. Jobvite, 2017. Retrieved from: https://www.jobvite.com/recruiting-process/top-three-talent-acquisition-strategies-2017/

[16] Stone, R. Human Resource Management (4th ed.). Australia: John Wiley and Sons Ltd., 2002. Retrieved from: https://trove.nla.gov.au/work/6924996

[17] Syed, M. P. and Ahmed, B. A Study on Talent Management Strategies in IT Industry. International Research Journal of Engineering and Technology (IRJET), 2007. Retrieved from: https://www.irjet.net/volume4-issue4 